\title{
EXTRAÇÃO LÍQUIDO-LÍQUIDO APLICADA A REDUÇÃo DA ACIDEZ DE BIOCOMBUSTÍVEIS - EFEITO DE VARIÁVEIS DE PROCESSO
}

\author{
A. A. MANCIO ${ }^{1}$, E. S. PAMPOLHA JUNIOR ${ }^{2}$, M. E. C. CORDEIRO ${ }^{2}$, N. T. MACHADO ${ }^{3}$ \\ ${ }^{1}$ Universidade Federal do Pará, Discente do Programa de Pós-Graduação em Engenharia de \\ Recursos Naturais da Amazônia (PRODERNA) \\ ${ }^{2}$ Universidade Federal do Pará, Discente da Faculdade de Engenharia Química \\ ${ }^{3}$ Universidade Federal do Pará, Docente da Faculdade de Engenharia Química \\ e-mail para contato: dedeiamm@yahoo.com.br
}

\begin{abstract}
RESUMO - Os biocombustíveis gerados por craqueamento termocatalítico têm quantidade substancial de ácidos orgânicos, principalmente, ácidos carboxílicos. Portanto, o presente trabalho tem como objetivo principal investigar três variáveis (temperatura, solvente e teor de água no solvente) importantes na extração líquidolíquido como um processo alternativo para reduzir a acidez de biocombustíveis ácidos gerados por craqueamento termocatalítico, visando a prevenção de corrosão durante o processamento. A acidez dos biocombustíveis foi determinada segundo o método padrão ASTM D974, o qual fornece o Número de Ácidos Totais (NAT). Nos experimentos, um biocombustível com NAT igual a 51,6 mg KOH/g foi submetido a um contato com um solvente adequado (álcool etílico ou álcool isopropílico) para a realização da desacidificação em temperaturas distintas, 25 e $35^{\circ} \mathrm{C}$, e cinco teores de água. Os resultados mostram que não houve efeito significativo das temperaturas e que a eficiência do solvente combinado (álcool etílico + água) foi levemente melhor do que o solvente combinado (álcool isopropílico + água) em relação à remoção de AGLs. Os melhores resultados são obtidos com o menor teor de água para ambos os solventes combinados empregados neste estudo, os quais foram utilizou álcool etílico com $10 \%$ de água e álcool isopropílico com $20 \%$ de água, que conseguiram remover $48 \%\left(25^{\circ} \mathrm{C}\right)$ e $44 \%\left(35^{\circ} \mathrm{C}\right)$, respectivamente.
\end{abstract}

\section{INTRODUÇÃO}

O processo de craqueamento de óleos vegetais ou gorduras animais ocorrem em dois estágios sucessivos e distintos. O primeiro estágio, conhecido como craqueamento primário, é caracterizado pela formação de espécies ácidas através da decomposição das moléculas de triglicerídeos que ocorrem através da quebra de ligações $\mathrm{C}-\mathrm{O}$ dentro da parte glicerídica da cadeia do triglicerídeo. O segundo estágio é caracterizado pela degradação de ácidos produzidos no primeiro estágio levando a formação de hidrocarbonetos com propriedades similares aqueles 


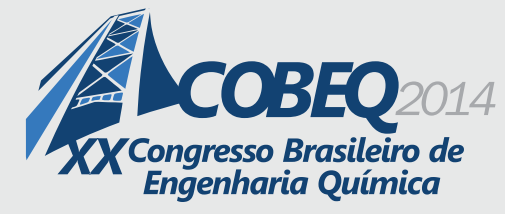

produtos do petróleo. Este estágio é chamado de craqueamento secundário (PRADO e ANTONIOSI FILHO, 2009).

Uma desvantagem do craqueamento é a acidez do produto final obtido, devido principalmente à presença dos ácidos carboxílicos na mistura (QUIRINO, 2006). Em alguns casos, o produto final apresenta quantidades significativas de ácidos graxos que elevam a acidez do biocombustível, podendo assim danificar o motor que utiliza derivados de petróleo (PRADO e ANTONIOSI FILHO, 2009). Um exemplo deste fato é apresentado na Tabela 1, onde o índice de acidez foi determinado com o objetivo de avaliar o conteúdo de ácidos graxos presentes nos produtos do craqueamento.

Tabela 1 - Índice de acidez dos produtos obtidos no processo de craqueamento em diferentes condições

\begin{tabular}{|c|c|c|c|}
\hline \multirow{2}{*}{ Sistema usado } & $\begin{array}{l}\text { Índice de acidez } \\
\text { (mg KOH/g) }\end{array}$ & \multirow{2}{*}{$\begin{array}{l}\text { Quantidade de } \\
\text { catalisador }\end{array}$} & $\begin{array}{l}\text { Índice de acidez } \\
\text { (mg KOH/g) }\end{array}$ \\
\hline & Biocombustível bruto & & Biocombustível bruto \\
\hline Craqueamento simples & 90,8 & 10\% de bauxita & 44,6 \\
\hline $\begin{array}{c}\text { Craqueamento simples } \\
\text { modificado }\end{array}$ & 44,6 & 20\% de bauxita & 35,0 \\
\hline Craqueamento fracionado & 82,7 & $30 \%$ de bauxita & 27,1 \\
\hline
\end{tabular}

Têm-se relatos na literatura de que biocombustíveis foram melhorados por adição de água ou soluções aquosas levemente básicas para neutralizar ou aumentar o pH dos mesmos (ZILNIK e JASBINSEK, 2012). Moens et al. (2009) estudaram a neutralização e a estabilização do biocombustíveis produzidos por pirólise rápida e usaram o NAT como uma indicação da mudança na acidez. Eles concluíram que o tratamento do biocombustível bruto com metanol na presença de um catalisador sólido ácido não é um processo eficiente para a neutralização e estabilização dos biocombustíveis brutos. Outras técnicas estão sendo exploradas para reduzir o NAT destes biocombustíveis.

Como certos componentes presentes no biocombustível apresentam pontos de ebulição similares, a destilação não pode ser usada como uma técnica de separação para produzir químicos oxigenados distintos ou frações bem definidas de químicos. A extração por solvente a temperatura ambiente e pressão atmosférica foi sugerida como uma operação unitária promissora para remover os compostos oxigenados dos biocombustíveis (ZILNIK e JASBINSEK, 2012).

WANG et al. (2001) investigaram a remoção de ácidos (desacidificação) por extração líquido-líquido em destilado de frações pesadas da indústria de petróleo. Porém, nenhum solvente econômico e adequado foi encontrado, inviabilizando sua aplicação na indústria do petróleo. Os métodos antigos focam principalmente no método álcool-amônia em que foi empregado álcool etílico, álcool isopropílico e assim por diante como solvente e amônia como componente da 


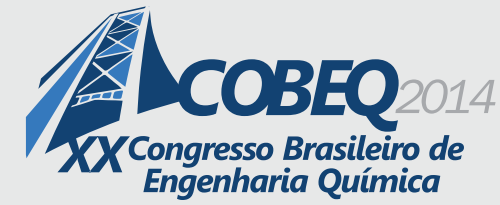

Engenharia Química
19 a 22 de outubro de 2014

Florianópolis/SC

desacidificação. A água foi geralmente adicionada para aumentar a massa específica do solvente combinado. Dados da refinaria de petróleo indicam que, quando o índice de acidez da matéria prima é menor do que $0,5 \mathrm{mg} \mathrm{KOH} / \mathrm{g}$, o processo de refino por extração líquido-líquido pode tornar o índice de acidez do óleo refinado inferiores a 0,03 $\mathrm{mg} \mathrm{KOH} / \mathrm{g}$.

Portanto, se os ácidos graxos livres (ácidos carboxílicos) forem removidos dos biocombustíveis, as propriedades de biocombustíveis melhorados estariam muito mais próximas da alimentação de hidrocarbonetos típicos do que o biocombustível original, e assim, o mesmo protocolo analítico aplicado para as alimentações das refinarias de petróleo poderiam ser usadas (OASMAA; ELLIOTT; KORHONEN, 2010).

Neste contexto, o desenvolvimento deste trabalho tem como objetivo principal investigar três variáveis de processo: (1) efeito da temperatura, (2) efeito do solvente e (3) efeito do teor de água no solvente sobre processo de desacidificação através de extração líquido-líquido, a partir do produto líquido orgânico extremamente ácido, obtido por craqueamento termocatalítico de óleo de vegetal realizado em uma planta piloto de craqueamento termocatalítico (FEQ/ITEC/UFPA).

\section{MATERIAL E MÉTODOS}

Uma amostra de Produto Líquido Orgânico (PLO) com número de ácidos totais (NAT) igual a 52,63 mg de $\mathrm{KOH} / \mathrm{g}$ e produzido por craqueamento termocatalítico do óleo de palma em escala piloto foi utilizada para avaliar o processo de desacidificação do PLO através da extração líquido-líquido empregando dois solventes combinados, sendo um destes constituído por uma combinação de álcool etílico (99,5\%) e água destilada e o outro composto de álcool isopropílico $(99,8 \%)$ e água destilada.

\subsection{Desacidificação por extração líquido-líquido}

Para a realização dos experimentos de desacidificação por extração líquido-líquido, manteve-se constante a razão mássica alimentação/solvente combinado de $1 / 1$ e as seguintes variáveis de processo foram alteradas: (1) temperatura do processo de desacidificação; (2) solvente combinado e (3) teor de água presente nos solventes combinados. Para a realização dos experimentos do presente trabalho, manteve-se constante a razão mássica alimentação/solvente combinado de $1 / 1$.

Efeito da temperatura: com o objetivo de avaliar o efeito da temperatura sobre o processo de desacidificação por extração líquido-líquido, foram selecionadas duas temperaturas diferentes: 25 e $35^{\circ} \mathrm{C}$.

Efeito do solvente combinado: com o objetivo de avaliar o efeito do solvente combinado sobre o processo de desacidificação por extração líquido-líquido, foram selecionados dois solventes diferentes: álcool etílico e álcool isopropílico. Quantidade de água pré-estabelecida foi adicionada a ambos os solventes a fim de aumentar a massa especifica dos mesmos e, dessa 


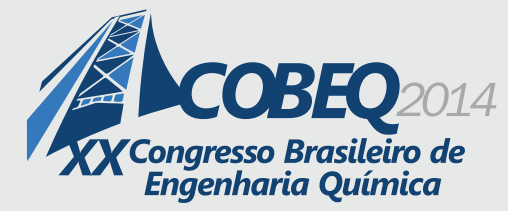

19 a 22 de outubro de 2014

Florianópolis/SC

forma, conseguirmos favorecer a formação das duas fases que é fundamental na extração líquidolíquido.

Efeito do teor de água presente nos solventes combinados: com o objetivo de avaliar o efeito do teor de água presente nos solventes combinados sobre o processo de desacidificação por extração líquido-líquido, foram preparadas cinco soluções (álcool + água) com teores de água diferentes, tanto para o álcool etílico como para o álcool isopropílico, conforme apresentado na Tabela 2.

Tabela 2 - Teor de água no solvente combinado empregado em cada experimento

\begin{tabular}{ccc}
\hline \multirow{2}{*}{ Experimentos } & \multicolumn{2}{c}{ Teor de água no solvente combinado (\%) } \\
\cline { 2 - 3 } & Etanol/Água & Isopropanol/Água \\
\hline Exp. 1 & 10 & 20 \\
Exp. 2 & 15 & 25 \\
Exp. 3 & 20 & 30 \\
Exp. 4 & 25 & 35 \\
Exp. 5 & 30 & 40 \\
\hline
\end{tabular}

Após a preparação das soluções (solvente combinado), pesou-se a massa de solvente combinado e a massa de produto líquido orgânico a fim de se ter uma razão mássica de alimentação/solvente combinado de 1/1. Em um vaso agitado de aço inoxidável e encamisado com capacidade de $2 \mathrm{~L}$ acoplado a um banho ultra-termostático com controle de temperatura, adicionou-se, primeiramente, o produto líquido orgânico e, em seguida, adicionou-se a massa de solvente combinado. Em seguida, agitou-se o material adicionado ao vaso por um período de 60 minutos para que o solvente combinado tivesse um contato adequado com a alimentação. Após o término da agitação, a mistura foi introduzida em um funil de separação e ficou em repouso até alcançar a separação total das fases. Neste estudo, cada experimento permaneceu em repouso por um período de $24 \mathrm{~h}$.

Passada o período de repouso, separou-se a fase leve da fase pesada. A fase leve (rafinado) é caracterizada pela presença de PLO desacidificado contendo um pouco de solvente combinado, enquanto a fase pesada (extrato) é caracterizada pela presença de solvente combinado e compostos ácidos extraídos do PLO. Em seguida, determinou-se o número de ácidos totais, conforme o método padrão da ASTM D 974 de ambas as fases, rafinado e do extrato.

\section{RESULTADOS E DISCUSSÃO}

\subsection{Efeito da temperatura sobre a desacidificação}

Duas temperaturas diferentes, $25^{\circ} \mathrm{C}$ e $35^{\circ} \mathrm{C}$, foram empregadas no processo de desacidificação de AGLs, por extração líquido-líquido, a partir de um produto líquido orgânico com número de ácidos totais (NAT) igual a 52,63 mg KOH/g com a finalidade de avaliar o efeito da temperatura sobre a remoção dos AGLs e, os resultados são apresentados nas Tabelas 3 e 4 e Figuras 1 e 2. 
Tabela 3 - Valores de número de ácidos totais (NAT) do rafinado para diferentes teores de água no solvente combinado (etanol + água) a 25 e $35^{\circ} \mathrm{C}$

\begin{tabular}{ccccc}
\hline \multirow{2}{*}{\begin{tabular}{c} 
Teor de água \\
\cline { 2 - 5 }$(\%)$
\end{tabular}} & \multicolumn{2}{c}{$\mathrm{NAT}(\mathrm{mg} \mathrm{KOH} / \mathrm{g})$} & \multicolumn{2}{c}{ Ácidos removidos $(\%)$} \\
\cline { 2 - 5 } $35^{\circ} \mathrm{C}$ & 27,901 & $25^{\circ} \mathrm{C}$ & $35^{\circ} \mathrm{C}$ \\
\hline 10 & 26,6901 & 27,7238 & 48,2349 & 45,8863 \\
15 & 27,2636 & 31,7495 & 37,1226 & 46,2300 \\
20 & 32,763 & 37,2489 & 36,4566 & 38,4222 \\
25 & 35,8142 & 36,8464 & 28,8747 & 27,7562 \\
30 & 36,6722 & & & 28,5369 \\
\hline
\end{tabular}

Tabela 4 - Valores de número de ácidos totais (NAT) do rafinado para diferentes teores de água no solvente combinado (álcool isopropílico + água) a 25 e $35^{\circ} \mathrm{C}$.

\begin{tabular}{ccccc}
\hline \multirow{2}{*}{$\begin{array}{c}\text { Teor de água } \\
\text { (\%) }\end{array}$} & \multicolumn{2}{c}{$\mathrm{NAT}(\mathrm{mg} \mathrm{KOH} / \mathrm{g})$} & \multicolumn{2}{c}{ Ácidos removidos (\%) } \\
\cline { 2 - 5 } & $25^{\circ} \mathrm{C}$ & $35^{\circ} \mathrm{C}$ & $25^{\circ} \mathrm{C}$ & $35^{\circ} \mathrm{C}$ \\
\hline 20 & 29,498 & 28,5979 & 42,7890 & 44,5347 \\
25 & 30,5361 & 31,6405 & 40,7756 & 38,6336 \\
30 & 30,4015 & 33,3865 & 41,0367 & 35,2473 \\
35 & 34,633 & 41,409 & 32,8297 & 19,6877 \\
40 & 36,9774 & 35,2255 & 28,2828 & 31,6806 \\
\hline
\end{tabular}

A partir dos resultados, observou-se que a remoção dos ácidos é pouco afetada pelas duas temperaturas empregadas no presente trabalho, ou seja, o aumento da temperatura de 25 para $35^{\circ} \mathrm{C}$ não favorece uma maior remoção dos ácidos graxos livres presentes no PLO.

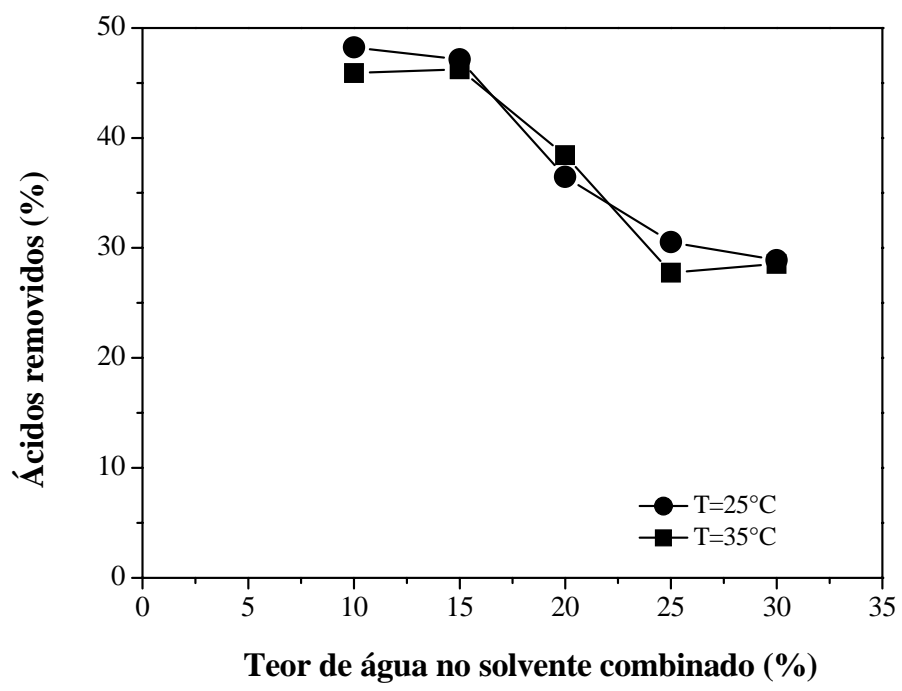

Figura 1 - Efeito da temperatura sobre a remoção de ácidos empregando solvente combinado (álcool etílico + água). 


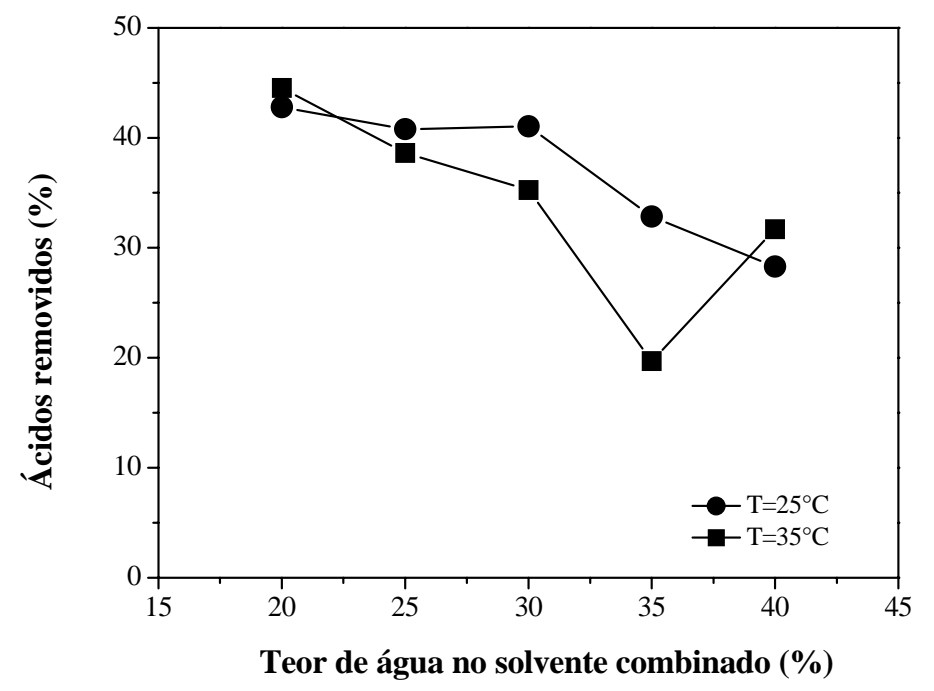

Figura 2 - Efeito da temperatura sobre a remoção de ácidos empregando solvente combinado (álcool isopropílico + água).

\subsection{Efeito do solvente combinado sobre a desacidificação}

Alem do efeito da temperatura também foi investigado o efeito do solvente combinado sobre a desacidificação, em que os resultados também são apresentados nas Tabelas 3 e 4 e Figuras 1 e 2.

Os resultados mostram que o solvente combinado formado por álcool etílico e água foi levemente mais eficiente na remoção dos AGLs presentes em um PLO com número de ácidos totais (NAT) igual a 52,63 $\mathrm{mg} \mathrm{KOH} / \mathrm{g}$ do aquele formado por álcool isopropílico. A pesar da diferença na remoção de AGLs entre um solvente combinado e outro não ter sido significativo, é notável no presente trabalho que a seleção do solvente é de fundamental importância na aplicação da extração líquido-líquido a desacidificação, assim como em outros processos investigados na literatura.

\subsection{Efeito do teor de água presente no solvente combinados sobre a desacidificação}

O efeito de cinco diferentes teores de água presente no solvente combinado sobre a remoção dos AGLs por extração líquido-líquido também foram estudados e, os resultados são apresentados tanto na Tabela 3 como na Tabela 4, para álcool etílico e álcool isopropílico a 25 e $35^{\circ} \mathrm{C}$. Tal efeito também pode ser visualizado através das Figuras 1 e 2.

De acordo com as tabelas e as figuras dispostas acima, observou-se que tanto a $25^{\circ} \mathrm{C}$ como a $35^{\circ} \mathrm{C}$ e independente dos solventes empregados no presente trabalho, o teor de água no solvente combinado tem um efeito significativo sobre a remoção dos ácidos graxos livres presente no PLO. Além disso, quanto maior o teor de água no solvente combinado seja álcool etílico ou 


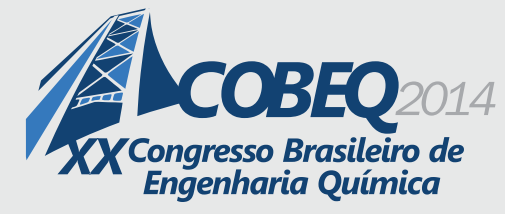

19 a 22 de outubro de 2014

Florianópolis/SC

álcool isopropílico, menor é a eficiência dos mesmos sobre a remoção dos AGLs, indicando que a quantidade de água deve ser a mínima possível, apenas o suficiente para aumentar a massa especifica do solvente a fim de separar as duas fases coexistentes (rafinado e extrato) no processo em questão, conforme foi feito por WANG et al. (2001).

Os melhores resultados deste estudo foram obtidos quando se utilizou álcool etílico com $10 \%$ de água a temperatura de $25^{\circ} \mathrm{C}$, condição em que o solvente combinado conseguiu remover um pouco mais de $48 \%$ de AGLs e, quando se utilizou álcool isopropílico com $20 \%$ de água a temperatura de $35^{\circ} \mathrm{C}$, condição em que o solvente combinado conseguiu remover em torno de 44\% de AGLs presentes no produto líquido orgânico produzido por craqueamento térmico catalítico de óleo vegetal.

\section{CONCLUSÃO}

A partir dos resultados obtidos no presente trabalho, verificou-se que não houve efeito significativo das temperaturas $\left(25\right.$ e $\left.35^{\circ} \mathrm{C}\right)$ empregadas sobre o processo de desacidificação por extração líquido-líquido. Alem disso, outras variáveis também foram investigadas e constatou-se que a eficiência do solvente combinado (álcool etílico + água) foi levemente melhor do que o solvente combinado (álcool isopropílico + água) em relação à remoção de AGLs. Por último, o teor de água presente no solvente combinado foi a variável estudada que realmente produziu um efeito sobre a remoção dos ácidos graxos livres, pois quando o teor de água no solvente foi elevada, notou-se uma redução na quantidade de AGLs removidos, ou seja, os melhores resultados são obtidos com o menor teor de água para ambos os solventes combinados empregados neste estudo, os quais foram utilizou álcool etílico com $10 \%$ de água e álcool isopropílico com $20 \%$ de água, que conseguiram remover $48 \%\left(25^{\circ} \mathrm{C}\right)$ e $44 \%\left(35^{\circ} \mathrm{C}\right)$, respectivamente.

\section{REFERÊNCIAS}

FRANK, T. C.; DAHURON, L.; HOLDEN, B. S.; PRINCE, W. D.; SEIBERT, A. F.; WILSON, L. C. Perry's Chemical Engineer's Handbook - Liquid-Liquid Extraction and Other LiquidLiquid Operations and Equipment (Section 15). 8th edition. McGraw-Hill, United States of America, 2008.\#

OASMAA, A.; ELLIOTT, D. C.; KORHONEN, J. Acidity of Biomass Fast Pyrolysis Bio-oils. Energy Fuels. V. 24, pag. 6548-6554, 2010.

PRADO, C.M.R.; ANTONIOSI FILHO N. R. Production and characterization of the biofuels obtained by thermal cracking and thermal catalytic cracking of vegetable oils. J. Anal. Appl. Pyrolysis. V. 86, pag. 338-347, 2009.

QUIRINO, R.L. Estudo do efeito da presença de alumina dopada com $\mathrm{TiO}_{2}$ e $\mathrm{ZrO}_{2}$ no craqueamento do óleo de soja. 2006. 67 f. Dissertação (Mestrado em Química) Universidade de Brasília, Brasília, 2006. 